\title{
Apropriação do Conceito de Divisão por meio de Intervenção Pedagógica com Metodologias Ativas
}

\section{Appropriation of the Division Concept by Means of Pedagogic Intervention with Active Methodologies}

\author{
Sônia Bessa* \\ ORCID iD 0000-0001-9857-6523 \\ Váldina Gonçalves da Costa** \\ ORCID iD 0000-0002-8636-7764
}

\begin{abstract}
Resumo
Nesse estudo são apresentados os dados de pesquisa que teve por objetivo verificar avanços de estudantes na compreensão da divisão após passarem por intervenção, quando comparados a estudantes que não passaram por tal intervenção. E ainda: observar ocorrência de relação entre aqueles avanços de compreensão com a intervenção realizada de estudantes do $4^{\circ}$ ano do Ensino Fundamental na resolução de situação problema envolvendo o conceito de divisão. Doze estudantes após um pré-teste foram alocados em dois grupos. Ao grupo experimental (GE) foi proposta intervenção pedagógica com metodologias ativas: jogos, desafios e situaçõesproblema. Foram 13 encontros semanais de 2 horas de duração. No pré-teste os dois grupos não diferiam entre si, apresentando o mesmo nível de compreensão da operação de divisão. Após a intervenção, os participantes do grupo experimental apresentaram expressivos progressos, nas condutas da divisão. Os participantes do grupo experimental superaram as dificuldades iniciais, o mesmo não sendo observado em relação aos participantes do grupo controle (GC).
\end{abstract}

Palavras-chave: Intervenção Pedagógica. Divisão. Metodologias Ativas.

\begin{abstract}
In this study, we present the data referring to a research aimed at verifying the students' progress in understanding division after going through an intervention, compared to students that did not go through this intervention. Also: we observe the occurrence of a relation-link between the comprehension progress, and the intervention carried out, with students in the $4^{\text {th }}$ grade of elementary education, in the solution of a problem situation involving the division concept. After a pre-test, twelve (12) students were divided into two groups; the experimental group (GE) received a pedagogic intervention with active methodologies: games, challenges and problem situations. We had thirteen two-hour weekly meetings during the research. In the pre-test, both groups presented the same level of understanding of the division process. After the intervention, the experimental group participants made expressive progress in the division sums. The experimental group students overcame their

\footnotetext{
* Doutora em Educação Pela Universidade Estadual de Campinas UNICAMP. Docente do Departamento de Educação da Universidade Estadual de Goiás-UEG Formosa, Goiás, Brasil. Endereço para correspondência: Rua 08 Quadra 53, Casa 25 Parque Vila Verde Formosa, Goiás, Brasil, CEP: 73808-335 E-mail: soniabessa@gmail.com.

** Doutora em Educação Matemática pela Pontifícia Universidade Católica de São Paulo PUC/SP. Docente do Departamento de Educação em Ciências, Matemática e Tecnologias da UFTM, Uberaba, Minas Gerias, Brasil. Endereço para correspondência: Rua Piauí, 462, Bairro Santa Maria, Uberaba, Minas Gerais, Brasil, CEP: 38050-460. E-mail: valdina.costa@gmail.com.
} 
initial difficulties, a fact which was not observed in the control group participants.

Key words: Pedagogic Intervention. Division. Active Methodologies.

\section{Introdução}

A divisão, ensinada nos Anos Iniciais do Ensino Fundamental, nem sempre é dominada pelos estudantes ao final dessa etapa. Para Taxa (2001, p. 5) "na escola os professores parecem não entender suficientemente os caminhos que as crianças percorrem para entender multiplicações e divisões”. Essa mesma perspectiva é defendida por Nunes e Bryant (1997, p. 17-18), "se desejamos ensinar matemática para crianças [...] temos que saber muito mais sobre como as crianças aprendem matemática e o que a aprendizagem da matemática pode fazer pelo pensamento delas". Para esses autores, "os professores frequentemente tentam ensinar às crianças conceitos matemáticos para os quais elas estão totalmente despreparadas" (NUNES; BRYANT, 1997, p. 17-18).

As operações de adição, subtração, multiplicação e divisão são apresentadas aos estudantes como um conjunto de técnicas, procedimentos e ações que se aplicadas repetidas vezes, condicionam à resposta correta. No caso da contagem, verificamos que é frequente crianças de 4 a 5 anos recitarem sequências numéricas; contudo, nem sempre essas contagens guardam relações com as quantidades que expressam. Alguns princípios lógicos como o princípio da correspondência termo a termo, da ordem, da cardinalidade e da indissociabilidade dos aspectos cardinal e ordinal do número nem sempre são compreendidos.

No caso das operações aritméticas, Kamii e Declark (1991, p. 93) enfatizam que “aprender a somar, subtrair e multiplicar envolve um raciocínio lógico matemático, e raciocínio não é técnica. $\mathrm{O}$ raciocínio não se desenvolve e nem pode ser aperfeiçoado meramente através da prática". A ênfase na memorização e nas respostas corretas, e não necessariamente na compreensão, tem sua utilidade quando se quer apenas o resultado.

Autores como Nogueira (2001), Pais (2001, 2006), Pavanello (2004) e Santos (2008) apresentam críticas quanto ao papel transmissivo da escola privilegiando em demasia os conteúdos conceituais e apontam a necessidade de rever a formação inicial dos professores.

Spinillo et al. (2017) concluíram que professores do $1^{\circ}$ ao $9^{\circ}$ ano do Ensino Fundamental têm dificuldades em formular problemas que envolvam diferentes relações no âmbito das estruturas multiplicativas, sendo necessário desenvolver com o professor do Ensino Fundamental a habilidade de formular problemas. Resultados similares foram verificados por Cunha (2015) em pesquisa com professores do Ensino Médio. Esses tiveram 
dificuldade em perceber as invariantes do conceito e as particularidades de cada tipo de problema, bem como contextualizar e estruturar os problemas combinatórios. Outro fator constatado foi a similaridade dos problemas com os encontrados nos livros didáticos.

Em algumas escolas é escassa a utilização de metodologias ativas que confiram uma participação maior às iniciativas e aos esforços espontâneos dos estudantes como atividades de manipulação e construção e a união do ensino e da pesquisa, especialmente para a solução de problemas novos ou ainda não resolvidos.

Para Gomes-Granell (1983, p. 276), "O processo habitual de ensino costuma ser ensinar um conceito ou algoritmo e depois expor um problema para comprovar se este foi adquirido ou não". Contudo, esse autor propõe outro caminho com situações que requeiram uma solução matemática e que permitam o levantamento de questões, a pesquisa, a discussão, a exploração e especulação e a contextualização das operações.

Para Nunes et al. (2002, p. 171) a aprendizagem escolar da multiplicação e divisão está mais centrada sobre o ensino de algoritmos do que sobre o desenvolvimento conceitual. “Ao aprender os algoritmos, os alunos deixam de refletir sobre as relações entre diferentes aspectos das situações que envolvem a multiplicação".

O ensino do algoritmo como uma técnica na qual os números são ensinados isoladamente pode promover duradouras dificuldades de aprendizagem. Kamii (2010) afirma que os algoritmos podem ser prejudiciais quando inseridos precocemente e descontextualizados: eles levam a criança a desistir do seu próprio raciocínio impedindo que os estudantes desenvolvam a noção de ordem e grandeza numérica; a criança desenvolve uma visão fragmentada do número, não o percebe como um todo, mas em cada unidade isoladamente.

Kamii (2015, p. 91) defende a inserção de situações de divisão em classes de primeiro ao quinto ano do Ensino Fundamental. Para essa autora, "problemas de divisão equitativa podem ajudar as crianças a aprender e compreender as frações”. Ela defende esse posicionamento uma vez que as operações aritméticas fazem parte do dia a dia das crianças. Ao considerar diferentes modos de resolução as crianças são desafiadas a explorar a quantidade global envolvida. De forma intuitiva estão estabelecendo relações entre os termos da divisão e a análise do resto.

Vergnaud (1986, p. 78) reitera que "os professores não deveriam ignorar o fato de as concepções dos alunos serem modeladas pelas situações da vida quotidiana e pela sua (primeira compreensão) das relações novas com que se deparam". 
Nunes et al. (2002) propõem que "problemas de multiplicação [...] já podem integrar o conteúdo do ensino de matemática a partir da $1^{\text {a }}$ série". Os estudos realizados por esses autores indicaram que as crianças dos Anos Iniciais já sabem resolver problemas de multiplicação de modo prático.

Estudos anteriores de Piaget e Zseminska (1981), Piaget (1996) e Nunes e Bryant (1997) já indicavam que crianças de 5 a 6 anos são capazes de resolver, no contexto prático, problemas envolvendo os conceitos de multiplicação e divisão intuitivamente. Outros estudos acrescentaram-se a esse, como os de Moro (2005), Lautert e Spinillo (2011), Fávero e Neves (2009), Lara e Borges (2012).

Vergnaud (1991) sistematizou tipos de divisão no âmbito das estruturas multiplicativas: a divisão por partição e a divisão por quotas. Em uma divisão como partição, (chamada de partitiva), tem-se, por exemplo, a seguinte situação: tenho 8 pêssegos e quero reparti-los com minha irmã - os 8 pêssegos e as duas irmãs - que resultarão em uma terceira, 4 pêssegos para cada irmã. São duas grandezas envolvidas: as maçãs e as duas pessoas, mas que resultará numa terceira. Esse tipo de raciocínio pode ser utilizado com crianças bem pequenas ainda que desconheçam os números, pois elas o fazem de maneira intuitiva.

$\mathrm{O}$ uso de procedimentos intuitivos ou estratégias pessoais para resolver cálculos ou problemas é um recurso didático. [...] a ideia que sustenta essa prática é que, utilizando os próprios recursos, os alunos resolvem operações e problemas com mais facilidade que aplicando símbolos abstratos e algoritmos convencionais (GÓMEZGRANELL, 1983, p. 176).

Zatti, Agraniohih e Enricone (2010) fizeram uma pesquisa com estudantes do $5^{\circ}$ ano do Ensino Fundamental com o objetivo de investigar os padrões de erros cometidos pelos alunos nas operações aritméticas. As autoras verificaram que a maior parte dos erros se concentram nas operações de divisão e subtração e não compreensão do algoritmo, refletindo o descompasso entre o tempo em que esses algoritmos são ensinados na escola e o tempo próprio de cada criança para a compreensão dos mesmos. Para a criança, a divisão só faz sentido quando está inserida em um contexto. Outro problema apontado por Carraher, Carraher e Schliemann (2011, p. 21) diz respeito à forma como o ensino de Matemática é feito, tradicionalmente, sem referência ao que os alunos já sabem. "Apesar de todos reconhecermos que os alunos podem aprender sem que o façam na sala de aula, tratamos nossos alunos como se nada soubessem sobre tópicos ainda não ensinados”.

Para Correa e Meirelles (2000), as situações de repartir que a criança encontra em sua vida diária podem ser resolvidas a partir de procedimentos aditivos em que a criança, através do uso da correspondência termo a termo, pode, então, estabelecer a equivalência entre as 
quotas a serem dadas a cada participante, adicionando ou retirando quantidades. No entanto, a divisão, como uma operação multiplicativa, vai requerer o entendimento, por parte das crianças, das relações entre dividendo e divisor na determinação do valor do quociente. No caso da divisão partitiva, o tamanho de cada quota dependerá da razão entre o quanto há para ser dividido e o número de quotas a serem dadas.

Correa (2004, p. 2) utiliza-se da distinção de Vergnaud (1991), quanto às duas classes de problemas de divisão: divisão partitiva e divisão por quotas. "Nos problemas de divisão partitiva, dados a quantidade a ser dividida e o número de quotas, pergunta-se à criança pelo tamanho da quota. Inversamente, nos problemas de divisão por quotas, é dado o tamanho da quota e pergunta-se, então, pelo número de quotas existentes”.

Correa e Meireles (2000) investigaram o entendimento intuitivo de divisão partitiva envolvendo quantidades contínuas entre crianças de 5 a 7 anos. Foi observado, com a idade, progressivo desenvolvimento das habilidades das crianças em lidar com a relação de ordem inversa entre divisor e quociente. Os resultados indicaram que a experiência em estabelecer comparações entre partilhas idênticas precede e parece constituir experiência fundamental à criança para a compreensão das relações entre os termos envolvidos na operação de divisão, principalmente no julgamento das relações de covariação inversa.

Correa (2004), em investigação com crianças de 6 a 9 anos, verificou que o desempenho dessas crianças foi influenciado pelo tamanho do dividendo e do divisor. Os procedimentos de dupla contagem e uso de fatos multiplicativos foram mais utilizados para a solução das tarefas de divisão por quotas, enquanto que procedimentos baseados no uso de adições repetidas e estratégias envolvendo partição de quantidades foram relativamente mais empregados nos problemas de divisão partitiva.

Dada a dificuldade dos estudantes com a operação de divisão por conta da complexidade, é importante que o professor disponha de um leque de opções para facilitar os processos de ensino e aprendizagem. Para Miguel (2005, p. 387), a abordagem tradicional apresenta somente um caminho: apresentação das propriedades do algoritmo e propor uma série de problemas para ilustrar a operação. "A tarefa do aluno geralmente se resume em descobrir a conta, fórmula ou procedimento algorítmico".

Kamii e Housman (2002), Kamii e Joseph 2008), Piaget (2010) e Gómez-Granell (1983) propõem metodologias ativas em que os estudantes sejam desafiados constantemente de forma prazerosa e interessante. Zunino (1996, p. 69) propõe aos estudantes descobrirem por si mesmos. "Eles poderiam descobrir progressivamente as maneiras mais econômicas de 
realizar as operações. Eles poderiam 'fazer matemática', em lugar de ver-se reduzidos a aplicar procedimentos que não compreendem".

A inserção de metodologias ativas pode ser determinante nos processos de aprendizagem. Ao se deparar com uma situação interessante de jogo ou de desafio, os estudantes buscam caminhos alternativos para a resolução dos cálculos e criam soluções próprias.

Piaget (2010, p. 60) atribui a responsabilidade do uso dos métodos ativos à escola. Cabe à escola promover uma "educação do espírito experimental e um ensino [...] que insista mais sobre a pesquisa e a descoberta do que sobre a repetição". Para Piaget (2010), somente em um ambiente de métodos ativos pode o aluno dar seu pleno rendimento, e só se compreende realmente os fatos e as interpretações quando se está dedicado pessoalmente a uma pesquisa.

Piaget apresenta os jogos como metodologias ativas ao afirmar que:

\begin{abstract}
A criança que joga desenvolve suas percepções, sua inteligência, suas tendências à experimentação, seus instintos sociais etc. É pelo fato do jogo ser um meio tão poderoso para a aprendizagem das crianças, que em todo lugar onde se consegue transformar em jogo à iniciação a leitura, ao cálculo, ou à ortografia, observa-se que as crianças se apaixonam por essas ocupações comumente tidas como maçantes (PIAGET, 2010, p. 158).
\end{abstract}

É importante que o educador tenha a preocupação de avaliar os recursos, partindo da ideia de que existe uma estreita relação entre a sua concepção sobre o ensino e sobre a aprendizagem e o uso de recursos didáticos. Não se trata apenas de saber quais conhecimentos transmitir, que jogos e desafios utilizar ou de como repassá-los, mas determinar qual concepção de ensino subjaz à atividade proposta. Trata-se de questão relevante, pois os recursos, mesmo os tecnológicos, podem ser utilizados com concepções epistemológicas baseadas somente na transmissão de conhecimentos e em concepções distorcidas de ciências. A forma como o estudante raciocina tem relação com a lógica da criança e a interação da criança com os materiais que lhes são disponibilizados.

Dessa forma, essa pesquisa objetivou investigar o nível de compreensão da operação aritmética de divisão (partição e quotas) de estudantes do $4^{\circ}$ ano do Ensino Fundamental. Para tanto, foi realizada uma intervenção pedagógica com jogos, desafios e situações-problema específicos para o desenvolvimento da operação de divisão por partição ou por quotas, vivenciada por parte dos estudantes (grupo experimental, GE). Ao final da intervenção, foi comparada a evolução da compreensão daquela operação dos estudantes desse grupo experimental com a evolução da mesma compreensão de estudantes não submetidos à intervenção (grupo controle, GC). 


\section{Metodologia}

Intervenção pedagógica é um modelo experimental do tipo pré-teste e pós-teste, segundo Campbell e Stanley (1979, p. 26), descrito como "delineamento experimental". Participaram 12 estudantes do $4^{\circ}$ ano do Ensino Fundamental de escola municipal localizada na região sul de São Paulo, encaminhados pelos professores como apresentando dificuldades de aprendizagem em Matemática. Os estudantes são da mesma escola, turno, ano escolar e idade, sendo 9 do sexo masculino e 3 do sexo feminino. Após o pré-teste (prova da operação de multiplicação e divisão) para definir os dois grupos (GE e GC) foi feito um sorteio, definindo-se aleatoriamente 6 estudantes para o grupo controle (GC) e 6 para o grupo experimental (GE).

Os estudantes do GE participaram de uma intervenção pedagógica, com ênfase na construção da operação aritmética de divisão (partição e quotas) com enfoque metodológico em jogos, desafios e situações problema, enquanto os estudantes do GC continuaram apenas com o ensino proposto na escola. Os dois grupos realizaram um pré e um pós teste conforme descrito adiante.

Os testes (pré e pós) consistiram em propor a seguinte situação: sobre uma mesa, o professor dispõe objetos, simulando uma loja. Cada objeto tem, à sua frente, um cartão com preços que variam de 1 a 9 e fichas, que correspondem ao dinheiro (cada ficha corresponde a $\mathrm{R} \$ 1,00)$. Pede-se ao estudante que constate o preço dos objetos e lhe propõe brincar de comprar e vender, sendo ele o comprador e o professor, o vendedor. O professor entrega para o estudante uma determinada quantidade de moedas (18) e pergunta-lhe quantos objetos de um determinado tipo podem ser comprados com aquele dinheiro. É-lhe proposto que pense se, com as mesmas moedas, poderá comprar algum outro objeto, dentre os existentes na loja, de maneira que não lhe sobrem ou faltem moedas. O estudante será avisado de que todos os objetos que poderá comprar deverão ser do mesmo produto. Esse problema foi proposto por Gómez-Granell (1983).

Trata-se de uma situação problema (prática), que envolve a ideia de quotas, cujo dividendo se mantém constante (18) e os divisores se limitam aos números 1, 2, 3, 6, 9 e 18. O desafio consiste em relacionar o valor dos objetos a esses divisores e excluir os números 4 , $5,7,8$, (divisores não exatos) e estimar a relação inversa entre o número de divisores e o tamanho do quociente.

Para avaliar os níveis de construção da operação de divisão, Gómez-Granell (1983) adotaram quatro condutas: conduta I - crianças que afirmam não poder comprar nenhuma 
outra coisa, ou somente objetos que custam $\mathrm{R} \$ 1,00$, não admitindo a possibilidade de fazer diferentes composições, nem mesmo com conjuntos equivalentes; conduta II - crianças que tentam operar com conjuntos equivalentes, mas ainda não fazem uma compensação exata entre o número de conjuntos e o de elementos de cada conjunto, dentro do mesmo todo. Parece haver um início de tomada de consciência de que, se comprar mais objetos, terão de ser mais baratos e vice-versa, sem que se chegue a uma quantificação exata. Não percebe a coordenação entre as variáveis: dividendo, divisor e quociente; conduta III - crianças que não são capazes de fazer antecipações corretas, mas chegam a uma solução, por meio de tentativas que vão desde um tateio assistemático, compreendendo algumas propriedades, até um tateio sistemático, com todas as possibilidades de distribuição do todo; e conduta IV - crianças que antecipam as possíveis composições do todo, com os respectivos conjuntos equivalentes, por meio de operações mentais, sem necessariamente se basear em comprovações empíricas. Essas autoras não mencionam os conceitos de divisão por partição ou por quotas proposto por Vergnaud (1991).

Após o pré-teste, foi realizada intervenção pedagógica com os seis estudantes do GE. O pré e pós-teste e a intervenção valeram-se do método clínico. O pesquisador, mediante suas ações ou suas perguntas, procura compreender a maneira como o estudante representa a situação e organiza sua ação.

Para o programa de intervenção foram selecionados jogos de regras, desafios e situações-problema, adaptados de Kamii e Joseph (2008), Macedo, Petty e Passos (2005) e Mantovani de Assis (2013), a descrição da atividade e a aprendizagem esperada estão relacionadas no quadro 1. As atividades enfatizaram: operações de adição, subtração, multiplicação e divisão, valor posicional, base 10, antecipação e cálculo mental. Foram 13 encontros semanais com duas horas de duração. $\mathrm{O}$ trabalho aconteceu em pequenos grupos de dois a três alunos, e no pré e pós-teste individualmente com a pesquisadora, para verificar a estabilidade dos avanços obtidos.

Para análise dos dados foi feito o registro escrito em tabelas e protocolos com o auxílio de gravação em áudio, mediante a autorização dos pais e da direção da escola.

\begin{tabular}{l|l}
\hline \multicolumn{1}{c|}{ Atividades/Jogos/Desafios } & \multicolumn{1}{c}{ Aprendizagem esperada } \\
\hline Jogo "Sempre 12" - realizar somas e & $\begin{array}{l}\text { Possibilita a realização de adições com unidades e } \\
\text { dezenas simultaneamente, favorecendo a construção }\end{array}$ \\
subtração com números que totalizem 12 \\
utilizando diferentes quantidades de \\
cartas*.
\end{tabular}




Pega Varetas: situação problema -
Calcular os pontos conforme o número de
varetas **
Jogo "memória de 10", "desça 10",
"pegue 10" - Ser capaz de realizar somas
que totalizem 10 através de diferentes
quantidades de cartas*.

Jogo "Marcando pontos" - Ser capaz de somar duas cartas com valores diferentes que totalizem $5^{*}$.

Jogo "Salve" - Realizar as operações
aritméticas de adição,
multiplicação e divisão*.

Jogo dos Palitos 1 e 2 - Formar figuras com uma quantidade $\mathrm{X}$ de palitos, multiplicando ou dividindo***

Jogo do buraco - inserir fichas simultaneamente com quantidades diferentes***.

Cálculo mental, correspondência termo a termo, adição e subtração, comparar quantidades, estabelecer relações de diferença, relacionar a parte e o todo.

Realizar adições e subtrações com unidades e dezenas simultaneamente por cálculo mental e considerar o valor posicional do número. Realizar adições cujo total seja 10 com diferentes quantidades de cartas.

Realizar adições e subtrações com unidades utilizando o cálculo mental.

No contexto de interação social, os alunos realizam operações de adição, subtração, multiplicação e divisão por meio de cálculo mental.

Operações de multiplicação e divisão, cálculo mental, relações de diferença, relacionar a parte e o todo simultaneamente.

Procedimentos de contagem até a operação de multiplicação e divisão. Enumerar e quantificar objetos numa relação termo a termo e ir progredindo até a multiplicação e divisão

Contando os pontos do dado - colocar Enumeração, relação termo a termo utilizando diferentes quantidades de fichas para cada adição, multiplicação e divisão por cálculo mental. ponto do dado que foi lançado*.

* KAMII, C.; JOSEPH, L. L. Crianças pequenas continuam reinventando a aritmética. 2. ed. Tradução de Vinicius Figueira. Porto Alegre: Artmed, 2008.

** MACEDO, L.; PETTY, A. L.; PASSOS, N. C. Aprender com jogos e situações problemas. Porto Alegre: Artmed. 2000.

*** MANTOVANI DE ASSIS, O. Z. Proepre Fundamentos Teóricos. 3a edição. Campinas: Book, 2013.

Quadro 1 - Jogos e desafios propostos no programa de intervenção Fonte: Dados organizados pela pesquisadora (2014)

\section{Resultados e Discussão}

A partir da análise do conteúdo dos protocolos das entrevistas dos estudantes, foi feita a classificação das condutas iniciais e finais da prova de multiplicação e divisão de GómezGranell (1983) e verificada a evolução, analisando-se a explicação e a estratégia utilizada pelo estudante para alcançar determinada resposta. As condutas do pré e pós-teste do grupo controle estão descritas na tabela 1 (a letra inicial do nome dos alunos foi substituída pelas primeiras letras do alfabeto).

No grupo controle (GC) somente o estudante "F" teve evolução no nível de conduta de divisão entre o pré e pós-teste. Saiu do nível de conduta I e foi para o nível de conduta II, os demais continuaram nos mesmos níveis de condutas, mesmo transcorridos quase dois meses entre o pré e pós-teste. Para 5 dos 6 estudantes avaliados não houve nenhuma mudança nos níveis de condutas de divisão. Esses 5 estudantes permaneceram no mesmo nível de conduta 
inicial.

Tabela 1 - Níveis de condutas da operação de divisão pré e pós-teste - grupo controle

\begin{tabular}{ccccc}
\hline $\begin{array}{c}\text { Alunos }-4^{\text {o }} \text { Ens. } \\
\text { Fundamental }\end{array}$ & $\begin{array}{c}\text { Ano } \\
\text { escolar }\end{array}$ & Idade & $\begin{array}{c}\text { Pré-teste } \\
\text { Condutas } \\
\text { Divisão }\end{array}$ & $\begin{array}{c}\text { Pós-teste } \\
\text { Condutas } \\
\text { Divisão }\end{array}$ \\
\hline 1. A & $4^{\circ}$ ano & 9 & I & I \\
2. B & $4^{\circ}$ ano & 9 & II & II \\
3. C & $4^{\circ}$ ano & 9 & I & I \\
4. D & $4^{\text {o }}$ ano & 9 & II & II \\
5. E & $4^{\circ}$ ano & 9 & II & II \\
6. F & $4^{\circ}$ ano & 9 & I & II \\
\hline
\end{tabular}

Fonte: Dados organizados pela pesquisadora (2014)

Descrever-se-á a seguir o diálogo inicial (pré-teste) entre a pesquisadora e o estudante "B". Foram dispostos sobre a mesa 9 grupos de objetos (minibrinquedos, apitos, skates, piões, carrinhos, beijos, vasinhos etc.). Cada grupo com 10 objetos iguais. "B" recebeu as 18 fichas e deveria comprar objetos de seu interesse, foi informado que cada ficha valia $\mathrm{R} \$ 1,00$ e que poderia comprar o que quisesse, um produto por vez, mas não poderia sobrar ou faltar dinheiro.

Trata-se de uma situação em que o dividendo se mantém constante e o divisor altera-se conforme o brinquedo escolhido. Ele só poderia utilizar os divisores 1, 2, 3, 6, 9 e 18, mas essa conclusão deveria ser um processo de descoberta do estudante, ele teria que relacionar o valor dos objetos a esses divisores e excluir: 4, 5, 7 e 8 . Como o dividendo foi mantido constante, o estudante teria que estimar a relação inversa entre o número de divisores e o tamanho do quociente. Os materiais disponíveis (lojinha) permitiriam que o estudante utilizasse a estratégia de formação de conjuntos equivalentes segundo a quantidade desejada e poderia livremente utilizar o material como suporte empírico. No pré-teste o estudante estava na conduta II e no pós-teste foi verificada a mesma conduta.

Após receber as 18 fichas para que comprasse o que quisesse, "B" disse que dava para comprar 4 tartarugas. Cada uma custava $\mathrm{R} \$ 8,00$.

Pesquisadora: Quanto você vai pagar por essas tartarugas?

B: $R \$ 40,00$.

Pesquisadora: Mas cada tartaruga custa $R \$ 8,00$, você tem certeza que dá para comprar?

B: (Ele parou e foi contando e separando os objetos, contava nos dedos, mas com muita dificuldade, ele disse): $R \$ 32,00$. (Mas percebeu que só tinha 18,00 e que não poderia comprar).

Pesquisadora: Tem algum objeto que daria para você comprar?

B: (Começou a separar os carrinhos que custavam $R \$ 1,00$ e após algum tempo disse): só tem 10 então não dá para comprar.

Pesquisadora: Olha bem, veja se tem mais alguma coisa.

B: (Escolheu 5 apitos que custavam $R \$ 2,00$ cada, e foi contando). Dá para comprar 5 apitos.

Pesquisadora: Como você descobriu?

B: Contei $2+2+2+2+2$.

Pesquisadora: Quanto dá então? 
B: (Contou novamente as fichas que estavam agrupadas em frente aos apitos de uma em uma e respondeu): $R \$ 10,00$.

(Diálogo entre a pesquisadora e o estudante “B”, registrado em áudio 2014).

O estudante "B" só conseguia calcular com o material e fazendo a correspondência objeto/ficha, limitava-se a contar todos os objetos de um em um, quando solicitado, para fazer uma correspondência com mais de um objeto teve dificuldade. Quando a noção ainda não está construída, há a necessidade de apoio de ações empíricas, como é o caso de "B": ele separa os objetos para criar uma ordem de contagem.

$\mathrm{O}$ estudante " $\mathrm{B}$ " poderia resolver o desafio das tartarugas de diferentes formas: fazer corresponder o número de fichas com o número de tartarugas, contaria $8+8$ e iria perceber que não poderia comprar por que o resultado final seria 16 e não 18. Outra forma de resolver seria selecionar o objeto mediado pela contagem. "B" foi contando de $1 \mathrm{em} 1$ até chegar à conclusão que 4 tartarugas custariam $\mathrm{R} \$ 32,00$ (ou 32 fichas) e que ele só tinha $\mathrm{R} \$ 18,00$. Não conseguiu antecipar, nem estimar a quantidade. O estudante fez os cálculos por aproximações sucessivas e com muita dificuldade. Ao comprar os carrinhos, ele teve menos dificuldade, pois a correspondência seria um a um e descobriu que poderia comprar 18 carrinhos.

Para comprar os apitos (custavam $\mathrm{R} \$ 2,00$ ) a dificuldade de "B" foi menor que comprar as tartarugas, pois cálculos envolvendo o número 2 foram mais fáceis para ele. Ele fez corresponder objeto/fichas, separou as fichas e foi colocando-as em correspondência; concluiu que compraria 5 apitos e gastaria $R \$ 10,00$. Para chegar ao cálculo de $R \$ 10,00$, ele disse que somou $2+2+2+2+2$. Ele faz a recontagem das quantidades já apresentadas, (apontando para os objetos) vai contando de um em um até atingir o valor do dividendo. Esse estudante do $4^{\circ}$ ano tem dificuldade em lidar com a relação parte-todo. Pelo tipo de resposta de "B" verifica-se que mesmo o raciocínio aditivo ainda está em fase de consolidação.

Para Nunes et al. (2002, p. 79), "quando resolvemos um problema de raciocínio aditivo, estamos sempre deduzindo algo que está baseado na relação parte-todo”. Esses autores acrescentam que "o raciocínio aditivo refere-se a situações que podem ser analisadas a partir de um axioma básico: o todo é igual à soma das partes” (idem, p. 78). Magina, Santos e Merlini (2014, p. 4), com base na teoria de Vergnaud, ampliam esse conceito e o compara com a multiplicação, esclarecendo que existe uma clara descontinuidade (ruptura) entre as operações de adição e multiplicação. "No raciocínio aditivo as situações podem ser analisadas a partir de um único invariante operatório, qual seja, a relação parte e todo - as partes são conhecidas e se procura o todo ou, ainda, o todo e uma das partes são conhecidos e se procura a outra parte". 
No pós-teste, não foi verificada evolução qualitativa na compreensão da operação de divisão do estudante "B", o qual permaneceu com dificuldades de relacionar o todo e as partes e não ultrapassou a conduta II da divisão.

A seguir será analisado o caso do estudante " $F$ " de nove anos que, conforme já exposto, no pré-teste estava no nível I da divisão e no pós-teste foi para a conduta II, sendo o único do grupo controle que apresentou evolução nas condutas de divisão.

Inicialmente "F" não conseguiu realizar a antecipação: chegava ao resultado, mas somente quando colocava os objetos numa relação termo a termo com as fichas. " $F$ " começou a fazer os agrupamentos de conjuntos equivalentes, mas logo se percebe capaz de ir contando as fichas sem necessariamente colocá-las em agrupamentos ou na frente dos objetos. Já utiliza o cálculo mental, para chegar ao cálculo final. "F" evoluiu em relação à avaliação inicial, chegando ao nível II da divisão que corresponde às crianças que tentam operar com conjuntos equivalentes, mas sem a compensação exata entre o número de conjuntos e o de elementos de cada conjunto, dentro do mesmo todo. Ainda não percebe a necessidade de coordenação entre as variáveis: dividendo, divisor e quociente.

Outro estudante do GC foi o aluno "C". Esse estudante não apresentou evolução entre os níveis de condutas do pré-teste e do pós-teste. Só conseguiu fazer os cálculos mediante a presença dos objetos, algumas vezes se referia às contas que aprendia em sala de aula, mas não sabia utilizá-las ou explicar os procedimentos. Piaget (1973, p. 12) explica esse fenômeno ao afirmar que "existe diferença entre aprender um resultado e formar um instrumento intelectual, uma lógica, necessária à construção de tal resultado". Esse estudante recorria frequentemente aos dedos para contar, mas não quis utilizar os palitos para realizar as operações. Aumentava intuitivamente o resultado final em algumas unidades, sem se preocupar com a quantificação exata. Não estabelecia relações entre o dividendo e o divisor. No pós-teste ao receber as 18 fichas para que comprasse o que quisesse, ele escolheu todos os vasos, (cada vaso custava $\mathrm{R} \$ 9,00$ ), colocou os vasos diante dele e foi fazendo cálculos nos dedos.

Pesquisadora: Você tem certeza que esse dinheiro dá para comprar todos esses vasos?

C: Vai sim (continuou contando, mas com muita dificuldade)

Pesquisadora: um menino me disse que como cada vaso custa $R \$ 9,00$ só dá para comprar 2 vasos, o que você acha?

C: (Parou e contou novamente e disse que ele gastaria $R \$ 89,00$ )

Pesquisadora: Então não dá para comprar, pois eu não te dei todo esse dinheiro?

C: (Foi colocando as fichas diante dos vasos cuidadosamente, até concluir que só compraria 2 vasos). Tentou comprar os carrinhos, $(R \$ 1,00)$ (foi colocando uma ficha diante de cada carrinho, mas disse que não daria porque não tinha carros suficientes).

Pesquisadora: Além dos vasos e carrinhos o que mais você compraria?

$\mathrm{C}$ : Apitos $(R \$ 2,00)$. 
Pesquisadora: Quantos apitos você compraria?

C: (Foi fazendo a relação termo a termo com os apitos e disse): dá para comprar 8.

Pesquisadora: Como descobriu?

C: Eu contei assim: (foi contando de 2 em 2 e por fim percebeu que havia feito a conta errada). Ah deu 9.

Pesquisadora: E o que mais você compraria?

C: Não dá para comprar mais nada.

(Diálogo entre a pesquisadora e o estudante “C”, registrado em áudio, 2014).

Esse estudante apresentou muita dificuldade. Não conseguiu perceber que se cada vaso custava $\mathrm{R} \$ 9,00$ e ele só tinha $\mathrm{R} \$ 18,00$ não poderia comprar 9 vasos. Inicialmente fez um longo cálculo, sem perceber a proporcionalidade. Para calcular o número de apitos que compraria utilizou o raciocínio da correspondência em coordenação com a contagem: apontava para os apitos e ia falando, 1, 2, 3, até chegar ao 9, se referindo ao número de fichas. Quando perguntado sobre o número de apitos, foi apontando e contando de 1 em 1 até chegar ao 9. Esteve mais próximo da resposta correta quando o divisor era 1 e 2 , mas não conseguiu relacionar o dividendo e o divisor; quando acertou, o fez por tentativa e erro. "C" não admitiu a possibilidade de fazer diferentes composições nem mesmo em conjuntos equivalentes, não conseguiu fazer nenhum tipo de antecipação e não apresentou nenhum princípio de compensação exata entre o número de conjuntos e o de elementos de cada conjunto dentro do todo. Fez várias tentativas de aproximações, sempre formando agrupamentos de fichas, o que ocorreu até mesmo quando os objetos custavam $\mathrm{R} \$ 1,00$. Percebe-se, também nesse estudante, a ausência de antecipação da solução numérica, fazendo os cálculos por aproximações sucessivas. No pós-teste não demonstrou nenhuma evolução nas condutas de divisão.

Quanto ao desempenho dos estudantes no pré-teste foi observada maior dificuldade dos participantes quando o divisor era maior; então, poderia existir alguma relação entre o tamanho do divisor e o desempenho. No caso desses participantes: quanto maior o divisor maior a dificuldade dos estudantes.

Os resultados entre o pré e o pós-teste dos alunos do GE podem ser visualizados na tabela 2.

Tabela 2 - Níveis de condutas pré e pós-teste - Grupo experimental

\begin{tabular}{|c|c|c|c|c|}
\hline & & & Pré-teste & Pós-teste \\
\hline $\begin{array}{l}\text { Alunos } 4^{\circ} \text { Ens. } \\
\text { Fundamental }\end{array}$ & $\begin{array}{c}\text { Ano } \\
\text { escolar }\end{array}$ & Idade & $\begin{array}{l}\text { Condutas } \\
\text { Divisão }\end{array}$ & $\begin{array}{c}\text { Condutas } \\
\text { Divisão }\end{array}$ \\
\hline $1 . \mathrm{G}$ & $4^{\circ}$ ano & 9 & I & II \\
\hline 2. $\mathrm{J}$ & $4^{\circ}$ ano & 9 & I & III \\
\hline 3. $\mathrm{K}$ & $4^{\circ}$ ano & 9 & I & III \\
\hline 4. $\mathrm{R}$ & $4^{\circ}$ ano & 9 & II & III \\
\hline 5. $\mathrm{S}$ & $4^{\circ}$ ano & 9 & I & III \\
\hline 6. V & $4^{\circ}$ ano & 9 & I & II \\
\hline
\end{tabular}

Fonte: Dados organizados pela pesquisadora (2014). 
Enquanto no pré-teste do GC somente 1 estudante evoluiu do nível de conduta I para a II, no pós-teste do GE todos os estudantes evoluíram para melhores condutas, ou seja, a intervenção realizada pode ter ocasionada avanço nos estudantes. É possível que as intervenções propostas com as metodologias ativas (jogos, desafios e situações problema) permitiram um avanço significativo na compreensão da operação de divisão.

Dos 6 estudantes que participaram da intervenção pedagógica, três evoluíram em uma conduta, sendo 2 da conduta I para a conduta II e um da conduta II para a conduta III e outros 3 evoluíram duas condutas, saindo da conduta I alcançaram a conduta III. Houve um progresso expressivo para os estudantes do GE; contudo, nenhum deles conseguiu alcançar a conduta IV, ou seja, ainda não dispõem de elaborações mentais que lhes permitam compreender que um número $\mathrm{X}$ de elementos pode ser dividido em conjuntos equivalentes, mantendo-se a compensação necessária entre o número de elementos de cada parte. Mas, é possível que se a intervenção tivesse se estendido por mais algumas semanas, esses estudantes chegariam à conduta IV da divisão.

A seguir serão apresentados alguns trechos da entrevista de pós-teste de estudantes do grupo experimental.

O estudante "J" que inicialmente estava na conduta I evoluiu para a conduta III no pós-teste. Na situação de divisão, "J” olhou os produtos e começou a pegar os skates:

Pesquisadora: $O$ que você está pensando em comprar?

$\mathrm{J}$ : Skates, eu comprei esses skates, porque no início eu ia comprar os piões, mas como cada um custa $R \$ 4,00$ iria sobrar $R \$ 2,00$ então eu comprei esses 6 skates.

Pesquisadora: Como você fez?

J: Cada skate custa $R \$ 6,00$ e $6+6+6=18$ e 6 X 3 ou 3 X 6 também dá 18.

Pesquisadora: $O$ que mais você compraria?

J: 9 apitos.

Pesquisadora: Como você descobriu?

J: Por que $9+9$ ou 2 X 9 vai dá 18.

Pesquisadora: $O$ que mais você compraria?

$\mathrm{J}: 18$ carrinhos.

Pesquisadora: Além dos carrinhos, apitos e skates, será que daria para comprar esses beijos que custam $R \$ 7,00$ ?

$\mathrm{J}$ : Não daria.

Pesquisadora: Por quê?

J: Ficaria faltando $R \$ 4,00$.

Pesquisadora: E as tartarugas que custam $R \$ 8,00$ ?

J: Não porque é o mesmo caso do 7, vai faltar.

Pesquisadora: E o que mais daria para comprar além desses?

$\mathrm{J}$ : Daria para comprar 2 vasos.

Pesquisadora: Como vocêfez para descobrir?

$\mathrm{J}$ : cada vaso custa $R \$ 9,00$ e dois vasos $=R \$ 18,00$.

Pesquisadora: Um garoto da manhã me disse que ele dividiria o 18 por 2 o que você acha desse jeito de fazer?

J: Dá para distribuir e saber também. 
Pesquisadora: quer fazer assim?

J: Com a tabuada de vezes é mais fácil.

(Diálogo entre a pesquisadora e o estudante "J", registrado em áudio, 2014).

Ao calcular, "J" começou a perceber diferentes formas de chegar ao resultado. Conseguiu perceber que com $\mathrm{R} \$ 18,00$ ele conseguiria comprar objetos, de 3, 2, 6, 9, 1 . Embora ainda recorra eventualmente ao processo aditivo, reconhece a multiplicação como outra forma de achar o resultado e já consegue antecipar as possíveis composições do todo, com os seus respectivos conjuntos equivalentes; faz isso por meio de operações mentais: conseguiu fazer todas as possibilidades de distribuição do dividendo, (18 fichas), mas em algumas situações ainda se baseava em comprovações empíricas. "J" tomou como referência a multiplicação para chegar à divisão. Ele precisava descobrir quantas vezes uma determinada quantidade estava contida na quantidade maior (18) e uma das estratégias utilizadas foi recorrer à multiplicação. Ele deixa claro que compraria 3 objetos no valor de $\mathrm{R} \$ 6,00$ porque “6 X $3=18$ ou 3 X $6=18$ ".

Segundo Correia (2006), os problemas de divisão por quotas demandam maior compreensão da relação inversa - a multiplicação entre quociente e divisor para se chegar ao valor do dividendo - podendo ser solucionados pela operação de multiplicação. Para Nunes et al. (2002, p. 78) o problema por cotas é o inverso da multiplicação, uma vez que "os alunos resolvem o problema com a mesma estratégia que utilizam para resolver problemas de multiplicação".

Outra estratégia utilizada por "J" para resolver o problema foi a repetição aditiva, pois ele adicionou a quantidade repetidas vezes até atingir o valor do dividendo. Usando a estratégia de cálculo mental, utilizou os esquemas da adição de juntar, separar e colocar em correspondência um a um baseado na relação parte todo, mas também admitiu a possibilidade de corresponder um a muitos no contexto da multiplicação.

Quando perguntado se poderia dividir 18 por 2, ele responde que poderia distribuir para descobrir. Nessa resposta está implícito que "J" admite a possibilidade de corresponder e distribuir como uma forma de resolver o desafio. Verifica-se pelas respostas que ele admite que não daria para comprar as tartarugas porque cada uma custa $\mathrm{R} \$ 8,00$. Por cálculo mental (sem o auxílio do algoritmo), calcula $2 \times 8=16$ e $18-16=2$. Utilizou conhecimentos prévios de subtração e multiplicação e um fato numérico conhecido para encontrar outro fato numérico.

Considerando-se que a divisão por quotas é uma operação complexa porque envolve outras operações como adição, multiplicação e subtração, o desenvolvimento do aluno "J" foi 
notável no pós-teste, saiu da conduta I no pré-teste e parece estar numa fase transitória entre a conduta III e IV de divisão. Foi uma evolução significativa.

O aluno "S" também teve evolução surpreendente entre o pré e pós-teste. No pré-teste estava na conduta I da divisão, tinha apenas uma consideração intuitiva da correspondência múltipla, sem considerar a quantificação exata. Só conseguiu chegar ao resultado final por procedimentos aditivos. Teve dificuldade de chegar ao fim da atividade, alegando que não conseguiria comprar nenhum produto e pediu para não concluir a atividade, demonstrando enfado.

No pós-teste ele chegou a solução por meio de tentativas: inicialmente, fez tateios assistemáticos até um tateio sistemático considerando todas as possibilidades de distribuição do todo. Ainda se valeu de procedimentos empíricos no início da atividade, mas conseguiu antecipar mentalmente alguns resultados, como o 3 X $6=18$. Queria comprar objetos que custavam $\mathrm{R}$ \$ 6,00; mas não utilizou imediatamente a divisão, recorrendo à multiplicação tal qual o estudante "J". Ou ainda quando multiplicou 3 X 10 e deduziu 3 para chegar ao resultado de $3 \times$ 9, parece ter chegado a alguma compreensão da propriedade distributiva, embora não sabendo explicitá-la. Foi capaz de relacionar os objetos de um lado e do outro lado a quantidade necessária de fichas, por cálculo mental, sem recorrer a contagem ou a correspondência termo a termo como fizera no pré-teste. Articulou todas as operações simultaneamente, foi capaz de antecipar e chegou ao resultado correto por procedimentos aditivos e multiplicativos. Embora tenha utilizado procedimentos aditivos, reconhece a possibilidade de utilização da multiplicação e divisão. Foi capaz de fazer a antecipação da quantidade de fichas que seriam necessárias, sem nenhuma verificação empírica, alcançando o resultado final mentalmente. No pós-teste ele chegou ao nível de conduta III da divisão, o que demonstra uma evolução muito boa.

" $K$ " foi outro estudante que no início da intervenção não conseguia sequer perceber que poderia comprar os objetos que custavam $\mathrm{R} \$ 1,00$. Esse é um dos estudantes da amostra que mais evoluiu nas condutas de divisão. Ele evoluiu dois patamares de conduta de compreensão da divisão, partindo do patamar de conduta I para o III.

Logo, os estudantes "J", "K", e "S" evoluíram dois níveis de conduta de compreensão da divisão, partindo do nível de conduta I para o nível de conduta III, o que é um resultado altamente satisfatório e representa um salto qualitativo.

Alguns oscilaram entre uma conduta e outra, ora antecipando o resultado, ora necessitando de comprovação empírica (contar nos dedos, fazer marcas de contagem, contar 
grupos de fichas sem necessariamente fazer a correspondência empírica um a muitos etc.) ou ainda, fazendo o cálculo mentalmente.

No pós-teste o desempenho dos estudantes que participaram da intervenção pedagógica melhorou progressivamente. Houve um progresso na utilização do cálculo mental, verificou-se o uso espontâneo de procedimentos aditivos e multiplicativos. Utilizaram adição e subtração repetidas e estratégias de dupla contagem como, por exemplo, para saber que poderia comprar 9 apitos de $\mathrm{R} \$ 2,00$, o estudante ia contando $2,4,6,8,10,12,14,16,18$. Verificou-se o conhecimento de fatos aditivos e multiplicativos: o estudante respondeu que 9 +9 ou 2 X 9 seria 18.

Os estudantes que participaram da intervenção pedagógica obtiveram maior sucesso na resolução dos desafios, conseguiram resolver os problemas mesmo quando o divisor aumentava. No pré-teste os estudantes só obtiveram resultados com divisores 1 e 2, utilizaram diferentes recursos e estratégias para chegar ao resultado. O material concreto foi importante inicialmente, mas verificou-se ao longo da intervenção e no pós-teste, que os estudantes foram se desvencilhando do mesmo e recorrendo ao cálculo mental e realizando antecipações.

Todos os estudantes do GE recorreram à multiplicação para resolver a situação problema proposta. O uso de fatos multiplicativos pode, de alguma forma, ter sido influenciado pela memorização da tabuada, ou pelo fato dos problemas de divisão por quotas demandarem maior compreensão da relação entre quociente e divisor para chegar ao dividendo, o que facilitaria a utilização da multiplicação.

Em pesquisa realizada por Correa (2004) verificou-se que crianças utilizaram com mais frequência procedimentos baseados em fatos multiplicativos nos problemas de divisão por quotas. "Provavelmente as crianças estariam tirando partido do fato de terem sido ensinadas a gerar as tabuadas de multiplicação ( $\mathrm{n}$ vezes $\mathrm{x}$ dá $\mathrm{y}$ ), o que facilita encontrar quantas vezes determinada porção poderia ser obtida até chegar à quantidade especificada no dividendo" (CORREA, 2004, p. 10).

Esta situação de divisão deixou claro que os estudantes operam inversamente, ou seja, utilizam a operação inversa à divisão (a multiplicação), que é construída antes. Eles faziam a multiplicação ou mesmo adições sucessivas para solucionar um problema de divisão. Nenhum dos estudantes do (GE) usou a divisão para calcular a quantidade de objetos que se pode comprar com certa quantidade de dinheiro; eles fizeram a correspondência multiplicativa e alguns utilizaram procedimentos aditivos. Para Nunes et al. (2002, p. 91), “os alunos resolvem o problema (de divisão) com a mesma estratégia que utilizam para resolver problemas de multiplicação." 


\section{Considerações Finais}

Pelos resultados verifica-se que no pré-teste os dois grupos não diferiam entre si, apresentando o mesmo nível de dificuldade; porém, após a intervenção, os participantes do grupo experimental superaram as dificuldades iniciais, o mesmo não sendo observado em relação aos participantes do grupo controle.

As condutas dos estudantes do GE mostraram que o programa de intervenção pedagógica, foi capaz de provocar melhores condutas na operação de divisão. Os estudantes desenvolveram procedimentos sistemáticos de cálculo mental para a solução das tarefas de divisão. Foram capazes de descrever procedimentos com base na adição e na multiplicação e encontrar soluções para as tarefas propostas. Alcançaram níveis de compreensão da operação de divisão mais sofisticados e complexos do que os estudantes do GC, embora ambos os grupos tenham apresentado o mesmo nível de dificuldade por ocasião do pré-teste.

Nas situações de divisão por quotas, ou partitiva, propostas na intervenção pedagógica (quadro 1) e no pré e pós-teste ficou evidenciado que os estudantes operam inversamente, ou seja, utilizaram a operação inversa à divisão, a multiplicação, que é construída antes. Contudo, nenhum deles conseguiu chegar ao nível da conduta 4 da divisão que consiste em coordenar e antecipar as possíveis composições do todo, com os respectivos conjuntos equivalentes, por meio de operações mentais, sem necessariamente se basear em comprovações empíricas. Não utilizaram a divisão por quotas ou partitiva para calcular a quantidade de objetos que se pode comprar com certa quantidade de dinheiro; mas faziam a correspondência multiplicativa, mesmo que alguns ainda o fizessem por procedimentos aditivos. É possível que mediante esses resultados verificados que os estudantes chegassem a essa conduta com mais intervenções, priorizando situações de divisão por quotas ou partitivas.

A intervenção priorizou a interação adulto-criança e criança-criança. Houve momentos de discussões e reflexões. Os estudantes foram solicitados a expor seu ponto de vista, discutir e a refletir acerca dos seus processos de resolução e sua forma de raciocinar frente a uma situação problema ou jogo, levando-os à construção de procedimentos empregados na divisão por quota ou partitiva.

Ao final das intervenções e para favorecer a reflexão foram feitas questões como: o que você fez? Como fez? O que pensou na hora de fazer? O que você queria fazer? Como pensou assim? Como você fará para resolver o problema? Aos estudantes foi dada a oportunidade de se autocorrigirem a fim de perceberem seus erros e contradições.

Lautert e Spinillo (2011) explicam que, com a ajuda do professor, a criança pode 
tomar consciência de suas formas de pensar. O pensamento, então, torna-se objeto de reflexão e análise pela criança. Mas não só pela criança, como também pelo adulto que com ela interage; de forma que ambos passam a discutir os procedimentos empregados na resolução dos problemas.

Os resultados do pré e pós-teste permitem afirmar que a solução de problemas de multiplicação e divisão vai muito além da aprendizagem da tabuada, pressupõe a atividade do estudante, sua ação sobre o objeto do conhecimento. Ensinar técnicas não contribui para a real compreensão da noção em questão e pode até prejudicar a compreensão ou ainda impedir que eles construam procedimentos mais elaborados.

É importante que o professor estimule os estudantes a empregar seus próprios procedimentos. Para Molinari (2010), a aplicação de uma técnica não contribui para a compreensão dos conceitos. Gradualmente, na medida em que os estudantes forem solicitando e trazendo para a sala de aula suas dúvidas e curiosidades a respeito das formas convencionais (algoritmos), o professor pode ir lhes mostrando como se opera com esses procedimentos, mas dando-lhes tempo para que eles façam suas relações, comparações e garantindo que, quando eles não compreenderem os algoritmos, possam ainda, utilizar seus procedimentos próprios.

Esse estudo embora bem elementar quanto ao número de participantes apresenta uma importante conclusão quanto aos resultados do GE e do GC. A intervenção pedagógica no contexto de metodologias ativas pode contribuir significativamente para a construção das operações aritméticas de multiplicação e divisão.

O uso de metodologias ativas implica a comparação e análise, a capacidade de avaliar, monitorar e gerenciar procedimentos diversos de resolução dos problemas, pressupõe rever e alterar suas próprias hipóteses iniciais. Para Macedo, Petty e Passos (2005, p. 36) quando as crianças tornam-se agentes de seus próprios conhecimentos, "envolvem-se com maior facilidade, prestam mais atenção, divertem-se aprendendo e pensando". Ou ainda, como propõem Lautert e Spinillo (2011), a sala de aula poderia tornar-se um ambiente marcado por atividades de natureza metacognitiva em que o aluno é solicitado a tomar seu pensamento e suas formas de raciocinar como objeto de reflexão e análise.

\section{Referências}

CAMPBELL, D; STANLEY, J. Delineamentos experimentais e quase experimentais de pesquisa. Trad. R. A.T. Di Dio. São Paulo: E.P.U./Edusp, 1979. 
CARRAHER, T; CARRAHER, D; SCHLIEMANN, A. L. Na vida dez na escola zero. $16^{\text {a }}$ edição. São Paulo: Cortez, 2011.

CORREA, J; MEIRELES, E. S. A compreensão intuitiva da criança acerca da divisão partitiva de quantidades contínuas. Estudos de Psicologia. 5(1), p. 11-31, 2000.

CORREA, J. A resolução oral de tarefas de divisão por crianças. Estudos de Psicologia. 9(1), p. 145$155,2004$.

CUNHA, M. J. G. Elaboração de problemas combinatórios por professores de matemática do ensino médio. 2015. 137 f. Dissertação (Mestrado em Educação Matemática e Tecnológica) Universidade Federal de Pernambuco, Recife, 2015.

FÁVERO, M. H; NEVES, R. S. P. Competências para resolver problemas e para analisar a resolução de problemas: um estudo junto a professores, licenciandos, pedagogos e psicólogos. Psicol. Esc.

Educ. Campinas, n.1, v. 13, p. 113-124, 2009.

GÓMEZ-GRANELL, C. Procesos cognitivos en aprendizaje la da multiplicación. In: MORENO, M. La Pedagogía operatória: un enfoque constructivista de la educación. Barcelona: Laia, 1983. p. 129147.

KAMII, C.; DECLARK, G. Reinventando a aritmética: implicações da teoria de Piaget. Trad. Elenisa Curt; Maria C.M. Dias; Maria C.D.Mendonça. São Paulo: Ática, 1991.

KAMII, C.; HOUSMAN, L. B. Crianças pequenas reinventam a aritmética. Trad. Cristina Monteiro. 2. ed. Porto Alegre: Artmed, 2002.

KAMII, C.; JOSEPH, L. L. Crianças pequenas continuam reinventando a aritmética. Trad. Vinicius Figueira. 2. ed. Porto Alegre: Artmed, 2008.

KAMII, C. Os efeitos nocivos do ensino precoce dos algoritmos. Trad. Marta Rabióglio. In: MANTOVANI DE ASSIS (Org.) Jogar e Aprender Matemática. São Paulo. Book Editora, 2010. p. $39-48$.

KAMII, C. Frações: incentivando estudantes de quinto e sexto anos a inventar multiplicações. Trad. Marta Rabióglio. In: MOLINARI, A. et al. (Org.). Novos caminhos para ensinar e aprender matemática. São Paulo: Book, 2015. p. 81-92

LARA, I. C. M; BORGES, R. A resolução de problemas de divisão partitiva nos anos iniciais do ensino fundamental. VIDYA, n. 1, v. 32, p. 9-20. 2012.

LAUTERT, S.; SPINILLO, A. Estudo de intervenção sobre a divisão: ilustrando as relações entre metacognição e aprendizagem. Educar em Revista. Curitiba, Brasil, n. Especial 1/2011, p. 93-107, 2011. Editora UFPR. 2011.

MACEDO, L.; PETTY, A. L.; PASSOS, N. C. Os jogos e o lúdico na aprendizagem escolar. Porto Alegre: Artmed, 2005.

MACEDO, L.; PETTY, A. L.; PASSOS, N. C. Aprender com jogos e situações problemas. Porto Alegre: Artmed. 2000.

MAGINA, S. M. P; SANTOS, A. dos; MERLINI, V. L. O raciocínio de estudantes do Ensino Fundamental na resolução de situações das estruturas multiplicativas. Ciênc. Educ. Bauru, v. 20, n. 2, p. 517-533, 2014. 
MANTOVANI DE ASSIS. O. Z. Proepre Fundamentos Teóricos. 3 ed. Campinas: Book, 2013.

MIGUEL, J. C. O ensino de Matemática na perspectiva da formação de conceitos: implicações teórico-metodológicas. In: PINHO, S. Z.; SAGLIETTI, J. R. (Org.). Núcleos de Ensino - PROGRAD - UNESP. I ed. São Paulo - SP: Editora UNESP, v. I, p. 375-394, 2005.

MOLINARI, A. M. C. Representação e solução de problemas aritméticos de divisão: um estudo dos procedimentos empregados por alunos do ensino fundamental I. 253 f. Tese (Doutorado em Educação) - Faculdade de Educação, Universidade Estadual de Campinas, Unicamp. 2010.

MORO, M. L. F. Estruturas multiplicativas e tomada de consciência: repartir para dividir. Psicologia: Teoria e Pesquisa, n. 21, v. 2, p. 217-226, 2005.

NOGUEIRA, N. R. Pedagogia dos projetos: uma jornada interdisciplinar rumo ao desenvolvimento das múltiplas inteligências. 1. ed. São Paulo: Érica, 2001.

NUNES, T.; BRYANT, P. Crianças fazendo matemática. Trad. Sandra Costa. Porto Alegre: Artes Médicas, 1997.

NUNES, T. et al. Introdução a educação matemática. São Paulo: Proem, 2002.

PAIS, L. C. Didática da matemática: uma análise da influência francesa. 1. edição. Belo Horizonte: Autêntica, 2001. 258 p.

PAIS, L. C. Ensinar e aprender matemática. 2. ed. Belo Horizonte: Autêntica, 2006.

PAVANELLO, R. M. (Org.). Matemática nas séries iniciais do ensino fundamental: a pesquisa em sala de aula. 1. ed. São Paulo: Biblioteca do Educador Matemático, 2004. 143p.

PIAGET, J; SZEMINSKA, A. A Gênese do número na criança. Trad. Christiano M. Oiticica. 3 ed. Rio de Janeiro: Zahar, 1981.

PIAGET, J. Problemas de psicologia genética. Trad. Celia E.A. de Piero. Rio de Janeiro: Forense, 1973.

PIAGET, J. Biologia e conhecimento. Trad. Francisco M. Guimarães. Petrópolis: Vozes, 1996.

PIAGET. J. Psicologia e Pedagogia. Trad. Dirceu A. Lindoso; Rosa M. R. Silva. 6 ed. São Paulo: Forense Universitária, 2010.

SANTOS, V. M. A matemática escolar, o aluno e o professor: paradoxos aparentes e polarizações em discussão. Cadernos Cedes, Campinas, v. 28, n. 74, p. 25-38, jan./abr. 2008. Disponível em: <http://www.scielo.br/pdf/ccedes/v28n74/v28n74a03.pdf>. Acesso em: 09 mar. 2017.

SPINILLO, A. G. et al. Formulação de problemas matemáticos de estrutura multiplicativa por professores do ensino fundamental. Bolema, Rio Claro (SP), v. 31, n. 59, p. 928-946, dez. 2017.

TAXA, F. O. S. Problemas multiplicativos e processo de abstração em crianças na $3^{\mathbf{a}}$ série do Ensino Fundamental. 255 f. Tese (Doutorado) - Faculdade de Educação: Universidade Estadual de Campinas, 2001.

VERGNAUD, G. Psicologia do desenvolvimento cognitivo e didáctica das matemáticas. Um exemplo: as estruturas aditivas. Análise Psicológica, 1(5), p. 76-90, 1986. 
VERGNAUD, G. El niño, las matemáticas y la realidad: problemas de la enseñanza de las matemáticas en la escula primaria. México: Trillas. 1991.

ZATTI, F.; AGRANIONHI, N. T; ENRICONE, J., R. B. Aprendizagem matemática: desvendando dificuldades de cálculo dos alunos. Perspectiva, Erechim, v. 34, n. 128, p. 115-132, dezembro/2010.

ZUNINO, D. L. A Matemática na escola: aqui e agora. Trad. Juan Acuña Llorens. Porto Alegre: Artmed, 1996. 